\title{
A Modular Cage System Design for Continuous Medium to Large Scale In Vivo Rearing of Predatory Mites (Acari: Phytoseiidae)
}

\author{
Juan Alfredo Morales-Ramos and Maria Guadalupe Rojas \\ USDA-ARS National Biological Control Laboratory, Biological Control of Pests Research Unit, 59 Lee Road, Stoneville, MS 38776, USA \\ Correspondence should be addressed to Juan Alfredo Morales-Ramos; juan.moralesramos@ars.usda.gov
}

Received 26 September 2013; Accepted 20 October 2013; Published 9 January 2014

Academic Editor: Cleber Galvão

Copyright (C) 2014 J. A. Morales-Ramos and M. G. Rojas. This is an open access article distributed under the Creative Commons Attribution License, which permits unrestricted use, distribution, and reproduction in any medium, provided the original work is properly cited.

\begin{abstract}
A new stackable modular system was developed for continuous in vivo production of phytoseiid mites. The system consists of cage units that are filled with lima beans, Phaseolus lunatus, or red beans, P. vulgaris, leaves infested with high levels of the twospotted spider mites, Tetranychus urticae. The cage units connect with each other through a connection cup, which also serves for monitoring and collection. Predatory mites migrate upwards to new cage units as prey is depleted. The system was evaluated for production of Phytoseiulus persimilis. During a 6-month experimental period, 20,894.9 $\pm 10,482.5$ (mean \pm standard deviation) predators were produced per week. The production consisted of $4.1 \pm 4.6 \%$ nymphs and $95.9 \pm 4.6 \%$ adults. A mean of $554.5 \pm$ 59.8 predatory mites were collected per harvested cage and the mean interval length between harvests was $6.57 \pm 6.76$ days. The potential for commercial and experimental applications is discussed.
\end{abstract}

\section{Introduction}

Phytoseiid mites are very effective predators used mainly in biological control of spider mites, Tetranychus urticae (Koch); however, phytoseiids are known to provide effective control of other mite species and some insects like thrips and white flies [1]. Zhang [2] reported that at least 20 species of phytoseiids have been made commercially available and have been applied mainly on greenhouse plants. The phytoseiid that has been most widely mass-produced and sold commercially is Phytoseiulus persimilis Athias-Henriot. Phytoseiulus persimilis is an effective biological control agent of spider mites on vegetables in glasshouses [3-5] and growers around the world use $P$. persimilis to control T. urticae and other tetranychid mites on crops grown in greenhouses and in the field $[6,7]$. Other phytoseiid species produced commercially and used in augmentative biological control of greenhouse pests include Neoseiulus cucumeris (Oudemans), N. barkeri Hughes, N. californicus (McGregor), N. fallacis (German), Iphiseius degenerans (Berlese), and Galendromus occidentalis (Nesbitt) [2].
Current methods of mass production of phytoseiid mites such as $P$. persimilis rely on greenhouse growth of bean plants for spider mite production and later inoculation with the predatory mite. A pure spider mite culture, free of predators, is also required for rearing. Infested leaves from the pure culture are used to infest bean plants in a different greenhouse. A series of greenhouse benches are inoculated at weekly intervals to provide continuous supply of prey. Predators are later introduced to bean plants heavily infested with spider mites and grown for 2-3 weeks. A section of the bench is harvested when it has reached the maximum predator density [8]. Introduction of $P$. persimilis into the infested beans requires perfect timing to allow maximum spider mite reproduction without losing the plants to the mite infestation [8]. Predator harvesting often exposes the predators to stressful conditions of starvation and many are lost to inefficient collection methods.

Enclosed rearing systems offer the potential of greater control of environmental conditions and better containment preventing excessive losses. Several methods for rearing phytoseiid mites in enclosed systems or cages by introducing 
prey have been proposed consisting of dishes with a central area limited by a channel filled with machine oil or other liquids [9-11].

Theaker and Tonks [12] reared $P$. persimilis in floating plastic leads positioned by magnets in the middle of a waterfilled container to prevent mites from escaping. A similar method based on a plastic foam block or sponge positioned in the middle of a tray filled with water was described by Overmeer [13] to rear several species including $P$. persimilis, P. macropilis (Banks), Typhlodromus occidentalis Nesbitt, T. pyri Scheuten, Amblyseius (Neoseiulus) fallacis (German), A. potentillae (German), and N. cucumeris (Oudemans). A barrier is formed by placing wet tissue paper around the block with one side touching the water to maintain a continuous saturation [13]. McMurtry et al. [14] describe a method of mass rearing of phytoseiid mites by washing eggs and other spider mite stages from infested leaves. The washed spider mites are then fed to predatory mites reared using the paperlined block in a water tray method as described by Overmeer [13]. Series of these trays are stacked inside shelved wood boxes. Shih [15] developed a method to separate the prey mites (T. urticae) from plant leaves and an apparatus which used pneumatic pressure to dispense a mix of the prey and corn pollen to rear Amblyseius womersleyi Schicha using the same lined semisubmerged block method.

Fournier et al. [16] proposed a cage system for rearing $P$. persimilis consisting of series of superimposing cylinders filled with bean leaves heavily infested by spider mites. New cylinders with infested leaves are added to the top of the series to supply new prey. The cylinders at the bottom are retired as predators move into cylinders with fresh prey [16]. Another cage system was described by Overmeer [13] consisting of two cardboard ice cream containers glued together and separated by a screen. Infested leaves are placed in the lower side and predators are introduced. New leaves are placed in the upper side where predators tend to move to find new prey. The whole system is flipped over to place new leaves while removing the old material [13].

While many enclosed rearing systems have been effective to mass-produce phytoseiid mites commercially, none of the existing enclosed systems can match the production capabilities of the open greenhouse rearing methods. An increasing level of sophistication will be required to reach a comparable level of production using enclosed systems. The objective of this study was to develop and test a refined enclosed rearing system based on the Fournier et al. [16] cage series.

\section{Materials and Methods}

2.1. Rearing of the Prey. Spider mites, Tetranychus urticae Koch, were used as prey to feed the phytoseiid mites. Colonies of T. urticae were established from commercial stocks provided by Syngenta Bioline, Oxnard, CA, and were reared on red kidney beans, Phaseolus vulgaris L., and lima beans, Phaseolus lunatus L., cultivars Fordhook 242 and Henderson in a greenhouse. The greenhouse was divided into two areas by using a clear polyethylene curtain. Lima beans were grown in one-half of the greenhouse using $60 \times 20 \times 20 \mathrm{~cm}$

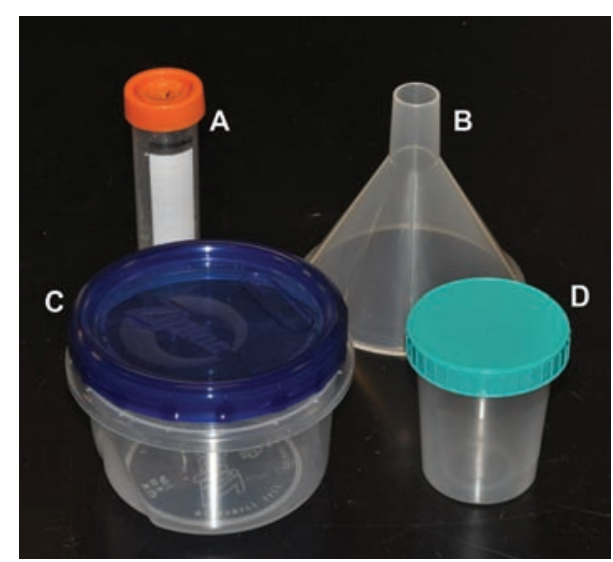

FIgure 1: Materials used to construct the cage system. (A) Polypropylene $50 \mathrm{~mL}$ centrifuge tube with screwed cover, (B) polypropylene $250 \mathrm{~mL}$ lab funnel, (C) polypropylene Ziploc storage containers, and (D) high density polyethylene $120 \mathrm{~mL}$ specimen containers.

polyethylene planters. The bottom of each planter was lined with $2.5 \mathrm{~L}$ perlite (Coarse, Sunshine, SunGro Horticulture, Bellevue, WA) to support and maintain humidity. A mixture of $2: 1$ potting soil (Moist control, Miracle-Gro Marysville, $\mathrm{OH}$ ), vermiculite (Coarse, Sunshine, SunGro Horticulture, Bellevue, WA), and $5 \mathrm{~g}$ slow release fertilizer $(\mathrm{N}: \mathrm{P}: \mathrm{K}=$ $14: 14: 14$ ) (vegetable and bedding, Osmocote, Marysville, $\mathrm{OH}$ ) was mixed and then combined with an equal volume of a mixture of $20 \mathrm{~g}$ TeraGel (T-400, The Terawet Corporation, San Diego, CA), $0.5 \mathrm{~g}$ water soluble fertilizer $(\mathrm{N}: \mathrm{P}: \mathrm{K}=$ $24: 8: 16$ ) (All-purpose plant food, Miracle-Gro, Marysville, $\mathrm{OH})$, and $2.5 \mathrm{~L}$ tap water. The aqueous solution was allowed to equilibrate for $24 \mathrm{~h}$ until the water was fully absorbed by the TeraGel crystals and then it was homogeneously incorporated into the potting soil and vermiculite mixture using a gardening trowel. Seventy seeds were planted and kept for 10 days in each planter for germination. Ten days after germination, planters with young bean plants were transferred to the second half of the divided greenhouse and plants were then massively infested with T. urticae by placing leaves from heavily infested plants on top of them.

Spider mite infestation levels were allowed to increase for 5 days after their introduction. Fully infested plants were monitored daily to determine optimal infestation levels. Extreme infestation levels kill the bean plants inducing massive migration of spider mites. Infested bean leaves were collected when they were still alive (leaves still green) and sustain a high density of spider mites. Infested leaves were collected daily by cutting them manually using garden scissors and placing them in plastic boxes. Boxes with infested bean leaves were stored at $15^{\circ} \mathrm{C}$ for 1 to 7 days.

2.2. Predatory Mite Rearing and Cage Design. Although the rearing system presented herein is suitable for any phytoseiid predator of spider mites, $P$. persimilis was used as the basis to test the system. The rearing system is based on the same principles of Fournier et al.s [16] stacked cage method, but 


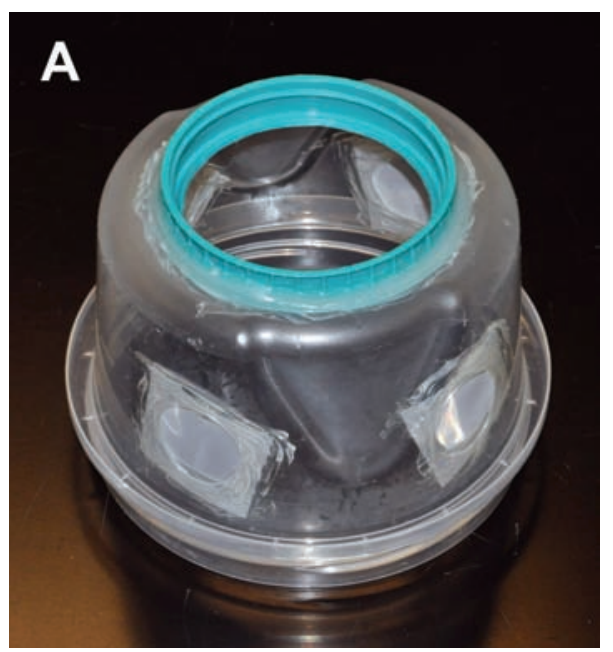

(a)

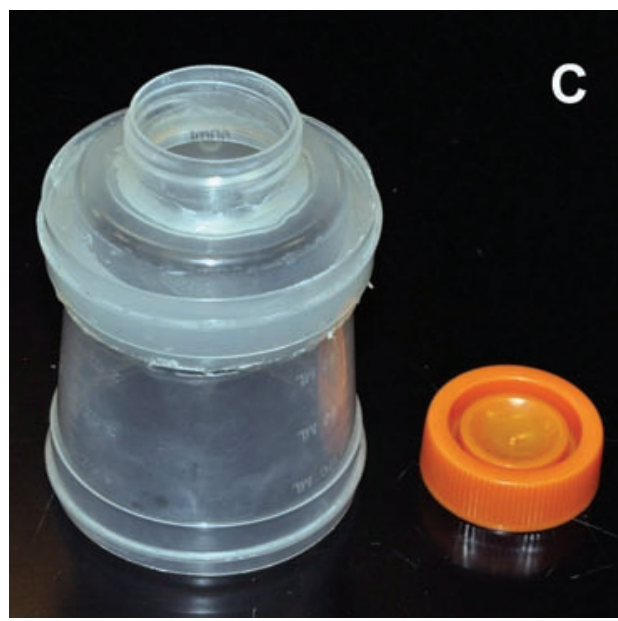

(c)

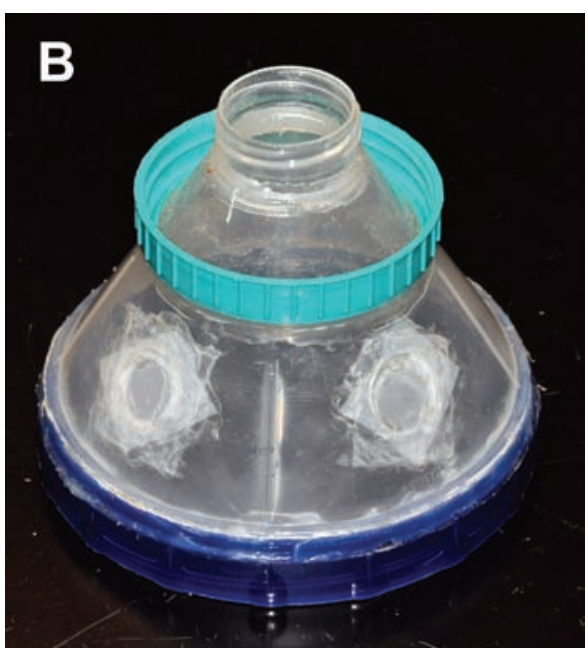

(b)

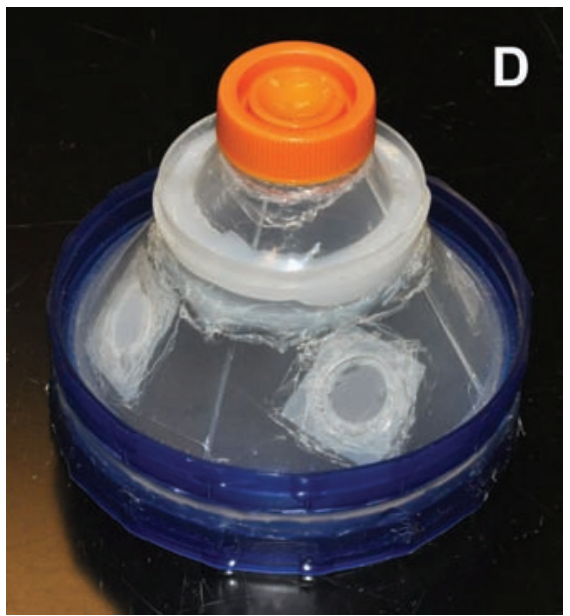

(d)

FIGURE 2: Basic cage system modular components. (a) Cage bottom, (b) cage cover, (c) connection cup, and (d) cage series stand.

we designed a unique modular structure of identical cage units. Stackable modular units were constructed from $473 \mathrm{~mL}$ Ziploc storage containers (Ziploc Twist'n Loc, S.C. Johnson \& Son, Inc., Racine, WI), $250 \mathrm{~mL}$ plastic laboratory funnels (Fisherbrand 10-500-2, $10.5 \mathrm{~cm} \mathrm{dia.} \times 10.3 \mathrm{~cm} \mathrm{H}$ ), plastic $50 \mathrm{~mL}$ centrifuge tubes (Corning No. 430897), and $120 \mathrm{~mL}$ specimen containers (LSS number 9BC-135972) (Figure 1). Materials for cage construction were chosen based on the quality of a water-tight screwed cover closure. Snap closures tend to fail with continuous use and mites quickly find escape openings. The cage system consisted of 4 basic parts that were modified to fit together: a cage bottom (Figure 2(a)), a cage cover with funnel connection (Figure 2(b)), a connection cup (Figure 2(c)), and a multiuse funnel to serve as stand (Figure 2(d)). The covers of the Ziploc containers (Figure 1(c)) were cut to allow the insertion of the lab funnels to the cage covers (Figure 1(b)). The tips (narrow ends) of the funnels were cut to install "male" screw sections of centrifuge tubes to allow closure when required (Figures 2(b) and 2(d)). "Female" screw sections of the covers of specimen containers
(Figure 1(d)) were cut and glued to the funnels and bottoms of the cage to allow connection with other cage units (Figures 2(a) and 2(b)). "Male" screw sections of centrifuge plastic tubes (Figure 1(a)) were also glued to the bottom of the connection cups (Figure 2(c)) to allow closure during mite collection and movement when connected to new cage units. Connection cups were also fitted with a second "male" screw section in the bottom allowing connection to both ends (Figure 3(c)). A cage unit consisted of bottom, top, and connection cup (Figure 3(a)). The system stand was used only in the starting cage (Figure 3(b)) and was fitted with a "male" instead of a "female" screw section from specimen containers (Figure 2(d)) to allow connection to the bottoms (Figure 2(a)) of the cages. Four circular windows ( $22 \mathrm{~mm}$ dia.) were cut on the sides of the cages bottom and four more (17 $\mathrm{mm}$ dia.) were cut on the sides of the funnels for ventilation. Only one circular window $(10 \mathrm{~mm}$ dia.) was cut on one side of the connection cups to reduce excessive loss of moisture. Nylon screen $85 \mu \mathrm{m}$ mesh (Small Parts Inc., $\mathrm{U}-\mathrm{CMN}-85$ ) was used to seal the windows preventing mites 


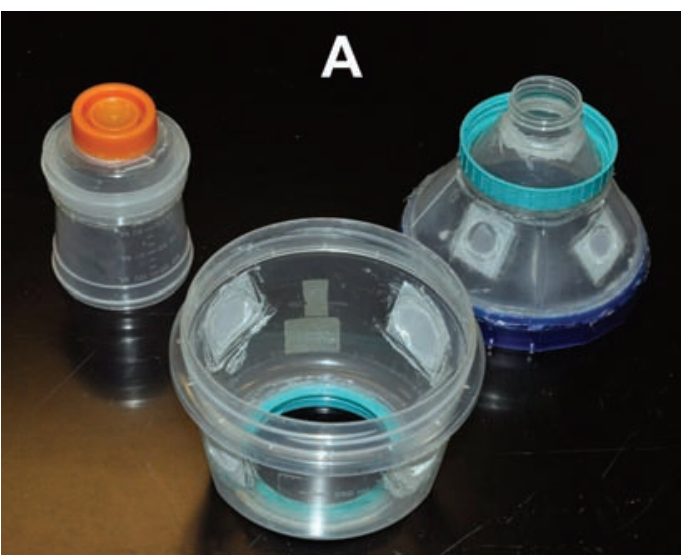

(a)

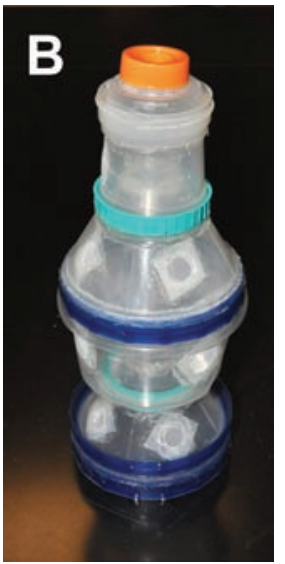

(b)

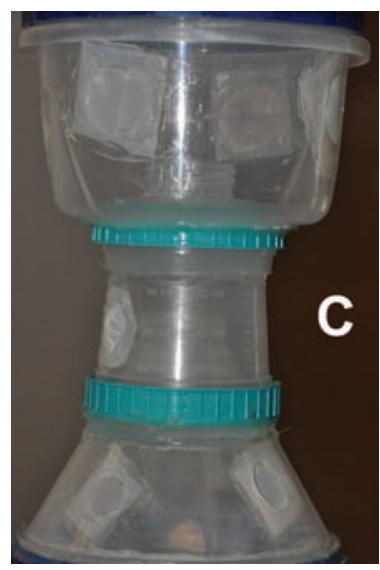

(c)

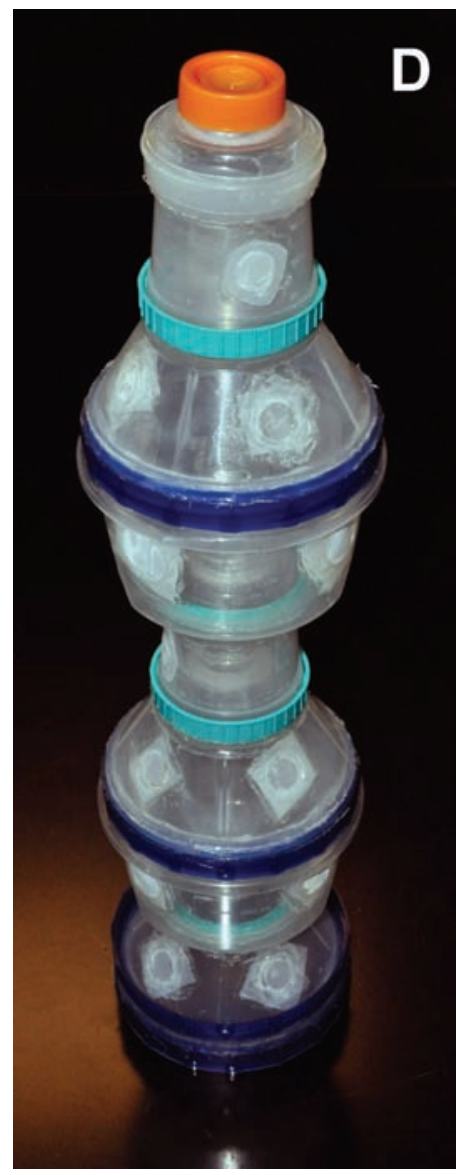

(d)

Figure 3: Cage system assembly. (a) Cage unit components, (b) cage unit assembled, (c) connection cup with second cage unit fitted, and (d) cage series assembly of two cage units.

from escaping. Cage units were designed to fit together in a modular way by connecting the bottom to the connection cup (Figures 3(c) and 3(d)).

Bean leaves heavily infested with T. urticae were placed inside each cage unit stacked vertically to allow mites to move up (Figures 4(a) and 4(c)). A cage series can be started by introducing a few adult predatory mites (10-100) into a cage unit newly filled with infested bean leaves. To start a cage series, a connection cup with mites is fitted to the bottom of a new cage unit (Figure 4(a) arrow and Figure 4(b)). This cup can later be replaced by the stand described in Figure 2(d) to provide better stability.

After prey mites had been depleted, a new unit is attached to the top of the old unit by removing the cover of the connection cup (Figure $4(\mathrm{~d})$ ) to allow predators to move into the new unit. The cover (full of predators) is placed inside the new unit (Figures 4(e) and 4(f)) and the cage is closed with a new funnel (Figures $4(\mathrm{~g})$ and $4(\mathrm{~h})$ ). A new connection cup is attached to the top of the funnel (Figure 4(i)) to complete the system (Figure $4(\mathrm{j})$ ). Nymph and adult predators tend to migrate to the upper end of the cage series and accumulate in the uppermost connection cup feeding on migrating spider mites.

2.3. Evaluation. The cage system was evaluated using $P$. persimilis as model. Evaluation started on 1 January 2007 by establishing 21 cage series. Each cage series started with approximately 100 adult predators. New cage series were created using predatory mites produced by the initial series. Some cage series had to be terminated and replaced due to contamination by other predatory mite species (Neoseiulus sp.) from the greenhouse spider mite production. Series increased in number to a maximum of 48 at the end of the study on 1 July 2007. The study was conducted in an environmentally controlled room at $26 \pm 1^{\circ} \mathrm{C}, 80 \pm 5 \% \mathrm{RH}, 14 \mathrm{~h}$ photophase, and $10 \mathrm{~h}$ scotophase.

Cage units were added to the top of each cage series as described above. Prey mites consisting of T. urticae were reared as described above using $P$. lunatus Henderson variety. When the connection cup contained a visibly high density of predatory mites, the cup was quickly disconnected from the 


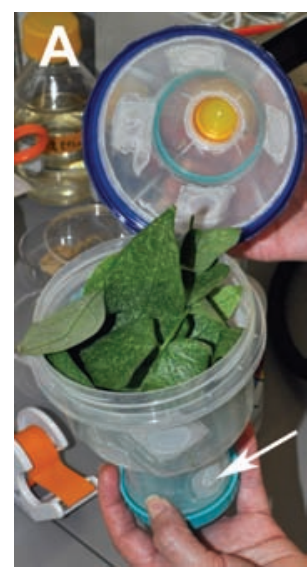

(a)

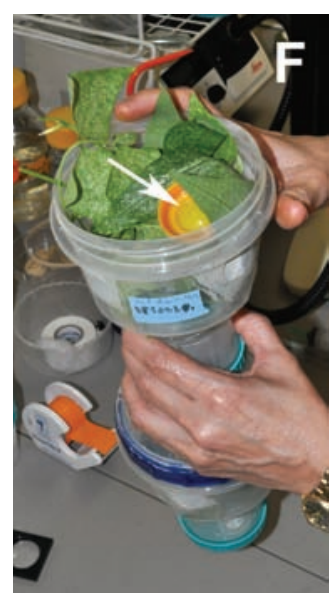

(f)

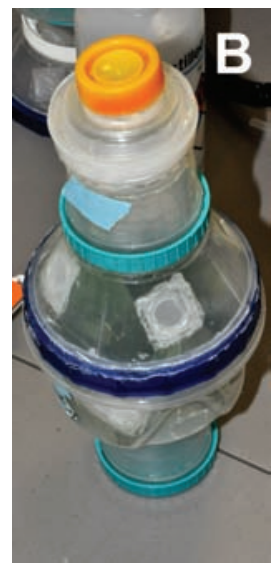

(b)

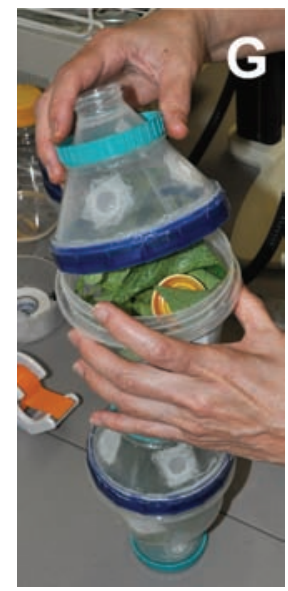

(g)

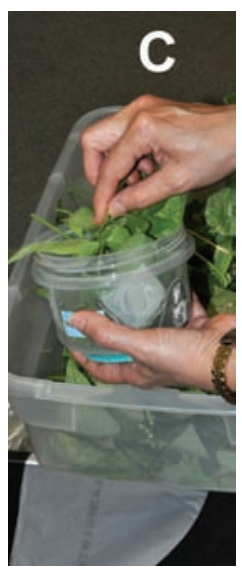

(c)

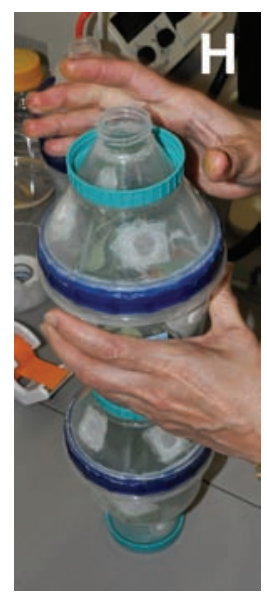

(h)

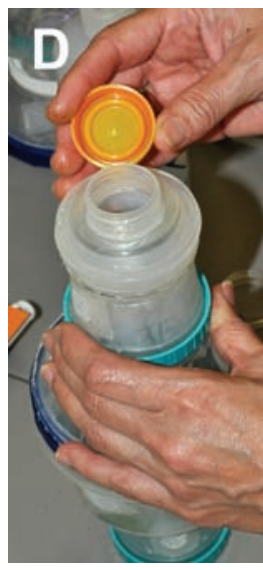

(d)

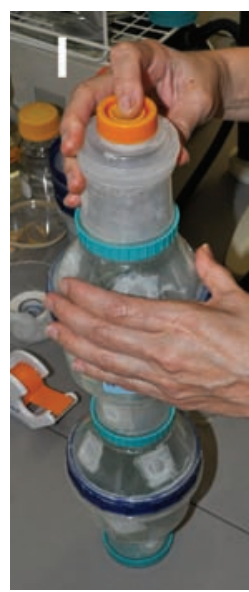

(i)

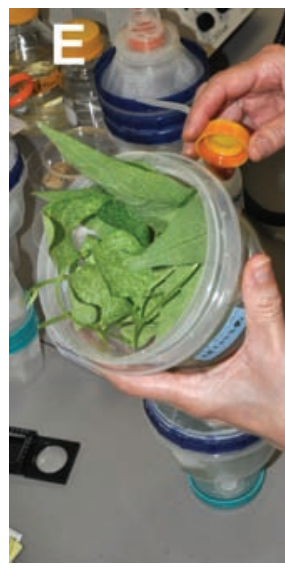

(e)

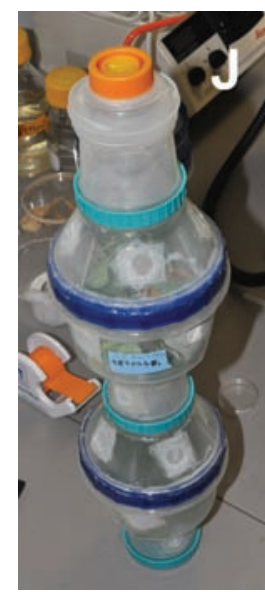

(j)

Figure 4: Cage system operation. (a) A cage series starts with a connection cup with predators connected to a cage bottom filed with spider mite-infested bean leaves. (b) The starting cage unit is closed and a connection cup is fitted. (c) When spider mites have been depleted by the predators, a new cage unit is prepared. (d) The cover of the connection cup is removed to allow predators to move to the new cage. (e) A new cage bottom is fitted to the connection cup. (f) The connection cup cover is placed inside the new cage. (g) The new cage is covered and (h) sealed, and (i) a new connection cup is fitted to the cover. (j) The process can be repeated by adding a third cage unit when prey has been depleted. At this point, the bottom connection cup can be replaced by the stand piece.

series, inverted, taped to make predator fall to the bottom, and filled with $70 \%$ ethanol to kill and preserve the predatory mites. Mites were counted and the numbers were recorded. Data consisting of days between harvest, collection date, cage series, and number of $P$. persimilis collected were recorded. Data were analyzed using single-variable statistics to determine means of mite production per week, mites produced per cage, and mean time from initiation to collection.

In this study, predatory mites were collected and killed with $70 \%$ ethanol in order to obtain precise numbers. However, live predators can be quantified while alive using less precise methods. One method is based on weight: first, a mean of individual weight is determined by weighing groups of mites in a precision balance; second, an empty collection cup (with cover) is weighed and used to collect predatory mites by attaching it to the top of the cage system. The cup full of mites can be closed (with the previously weighed cover) and weighed a second time. The weight of the live mites can be determined by subtracting the weight of the empty cup from the weight of the full cup. Another method consists of determining the number of mites fitting in a given volume. Mites can be forced by gentle vacuum into receptacles with known volume. When filled, the receptacle can be emptied by reversing the airflow.

\section{Results and Discussion}

During the six-month evaluation period, the mean weekly production was $20,894.9 \pm 10,482.5$ (mean \pm standard deviation) $P$. persimilis. Production consisted of $4.1 \pm 4.6 \%$ deutonymphs and $95.9 \pm 4.6 \%$ adults. Overall production mean was $554.5 \pm 59.8$ mites per harvested cage and a mean of $36.7 \pm$ 17.0 cages were harvested per week. The mean interval of time between harvests was $6.57 \pm 6.76$ days; however, the length of the harvest intervals did not have a normal distribution and the median was 4 days and the $75 \%$ quartile 
was 5 days (Figure 6). The top quartile consisted of intervals ranging from 6 to 62 days in length and the $90 \%$ percentile was 14 days. Based on this analysis, the time interval between harvests should not exceed 14 days. If by 14 days the population of predators is still too low to justify harvest, the cage series should be terminated and a new series should be generated from predator production of a healthy series.

The connection cup usually contains large quantities of spider mites, which constantly migrate when they are in high densities. As predatory mites increase in numbers, they consume all the prey in the connection cup. Juvenile predatory mites (young adults and deutonymphs) tend to rapidly migrate upwards to the new cage unit. Gravid adult females usually remain in the bottom cage unit until they oviposit. As the last eggs are oviposited and prey is depleted, females move upwards to the new cage unit. As the population of predatory mites increases, it becomes necessary to add new cage units within increasingly shorter periods of time. Empty cage units at the bottom can be removed after all the eggs have hatched and the juveniles have moved to new cage units. The connection cup at the top of the series serves as an indicator of predatory mite population. The predators in the connection cup may be recycled by fitting a new cage unit or harvested by removing the connection cup and closing it with an unmodified cover of a specimen container. Decision to harvest the predatory mites depends on the density of juveniles in the connection cup (Figure 5). Once the predatory mite population is well established in a cage series, it becomes necessary to harvest the predatory mites every 2 to 4 days depending on the quality of prey provided. Harvested mites can be used to start new cage series, for field releases, or for use in experiments. A cage series can be continuously producing predatory mites indefinitely as long as new cage units are added to the top of the series.

Peak weekly production occurred during the week between March 11 and 18 with a total of 38,097 adults and nymphs harvested (Figure 7(a)). During this period, 41 cage series were in operation (Figure 7(b)). Mean production per harvested cage was more or less consistent during the experimental period (Figure $7(\mathrm{c})$ ). The total weekly production dropped sharply by the end of the experiment even as the number of series increased; however, the number of mites per harvested cage was increasingly consistent evidenced by the decrease of the standard deviation (Figure $7(\mathrm{c})$ ).

A study of three-trophic-level impact of secondary chemicals present in lima beans showed that high levels of linamarin present in Henderson lima beans tend to accumulate in the predatory mites after several generations [17]. Accumulation of linamarin may have been the reason the production dropped by the end of the study even as the number of cage series increased. The use of this variety is not recommended for continuous production of phytoseiid mites. Fordhook 242 lima beans provide a better alternative because they contain only trace amounts of linamarin (M. G. Rojas unpublished). Henderson lima beans were selected for this experiment because they are easy to grow and the size of their leaves is optimal to fit inside the cages described in this study. Fordhook 242 lima beans have larger leaves, which must be folded or cut to fit in the cages. Another good choice

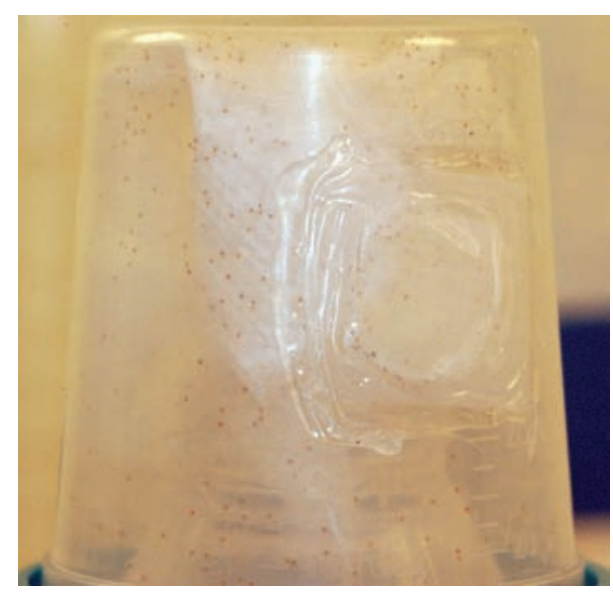

FIGURE 5: Connection cup with $P$. persimilis after prey had been depleted. A piece of paper can be introduced to the connection cup to increase the surface area.

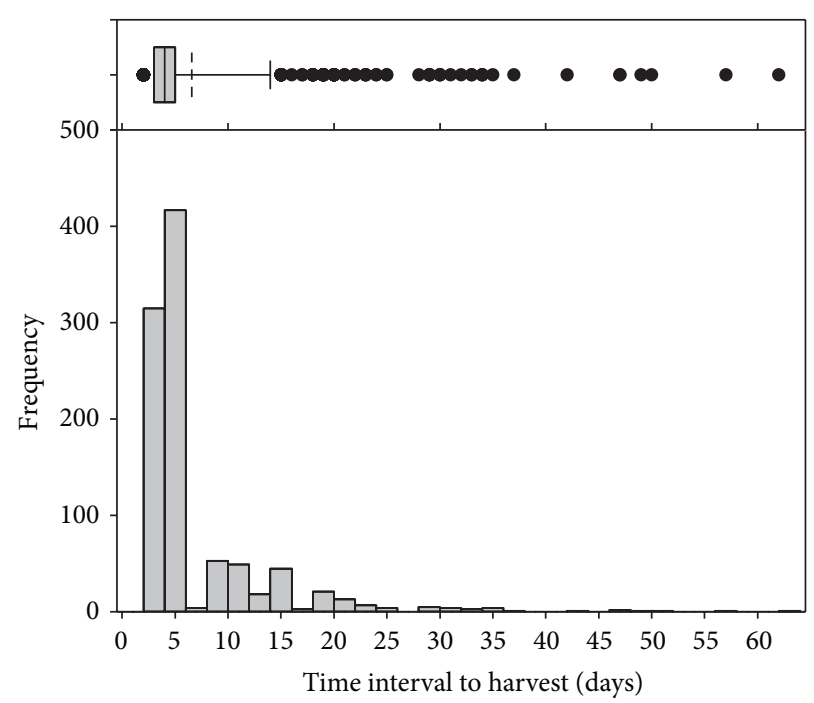

FIGURE 6: Frequency distribution of predator harvest intervals. Box plot (top): bars represent $25 \%$ and $75 \%$ quartiles, line between bars represents the median, dashed line represents the mean, bracket represents the $90 \%$ percentile, and dots represent outliers. Bar plot (bottom): bars represent 2-unit classes.

of host plant is red beans, which have similar leaf sizes to those in Henderson lima beans. However, a system could be constructed with larger cage units providing more space to accommodate larger leaves.

The size limits for the system have not been determined, but 8 liter (2-gallon) size units have been constructed and tested successfully (Figure 8). In theory, the system can be scaled up to accommodate production levels of millions of mites per week. Potential size limits include the structural integrity of currently available materials taking into account the weight of the leaves that must be held by the cage units. The tightness of the closures between cage unit connections can be more difficult as cage size increases. The tolerance of closures between cage units cannot exceed $100 \mu \mathrm{m}$ to contain 


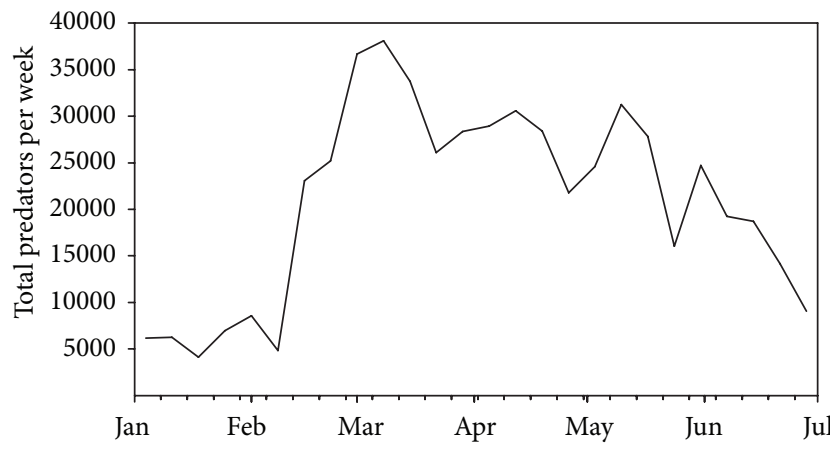

(a)

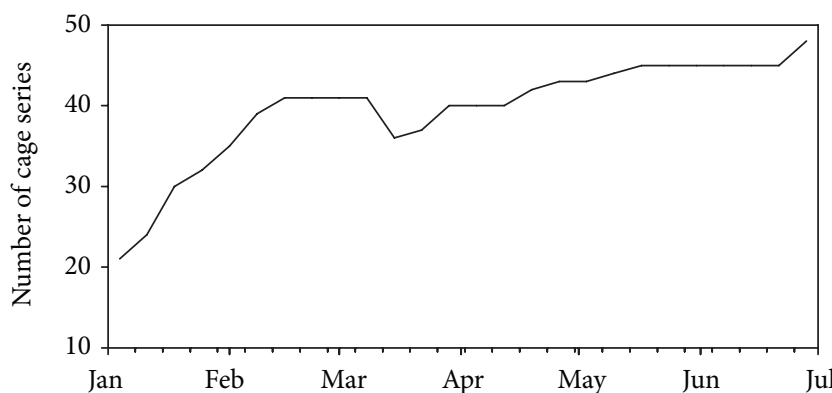

(b)

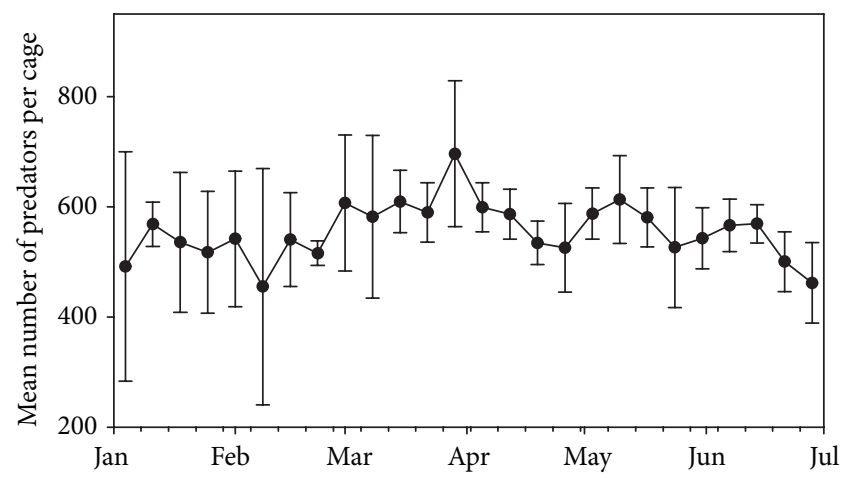

(c)

Figure 7: Production of $P$. persimilis. (a) Total weekly production. (b) Number of cage units in production. (c) Means of predators produced per harvested cage; brackets represent standard deviation.

the mites within the cages, and this becomes increasingly difficult as the size of the screw cups increases.

\section{Conclusions}

The modular cage system presented in this study has been shown to be a consistent and robust method to produce phytoseiid mites. The system is particularly suitable for medium to large scale rearing of $P$. persimilis. This system provides a good alternative for phytoseiid mites rearing and potentially can be scaled up for mass production.

\section{Conflict of Interests}

The authors declare that there is no conflict of interests regarding the publication of this paper.

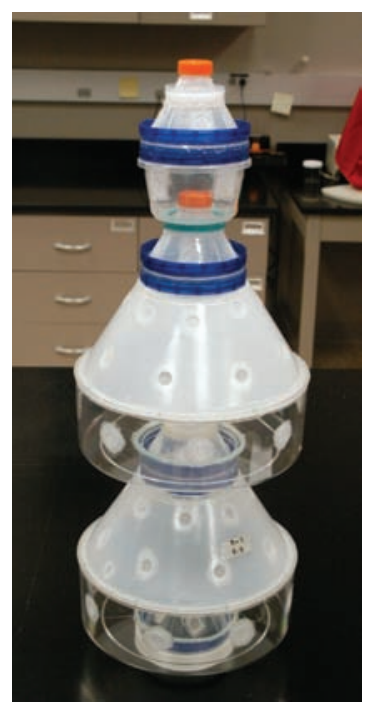

Figure 8: Larger size cage system design.

\section{Acknowledgments}

The authors thank D. Cahn, Syngenta Bioline, for providing the rearing stocks of $P$. persimilis and T. urticae and partial funding through CRADA agreement 58-3 K95-0-1428. They acknowledge the peer reviewers for their comments on an earlier version of this paper. The United States Government has the right to retain a nonexclusive, royalty-free license in and to any copyright of this paper. The mention of a commercial or proprietary product does not constitute an endorsement of the product by the United States Department of Agriculture (USDA). USDA is an equal opportunity provider and employer.

\section{References}

[1] K. J. F. Bolckmans, "Mass-rearing phytoseiid predatory mites," in Proceedings of the Working Group AMRQC, C. van Lenteren, P. DeClercq, and M. W. Johnson, Eds., vol. 3, pp. 12-15, Bulletin IOBC Global, 2007.

[2] Z. Zhang -Q, Mites of Greenhouses Identification, Biology and Control, CABI, Oxon, UK, 2003.

[3] D. A. Chant, "An experiment in biological control of Tetranychus telarius (Linneaus) (Acarina: Tetranychidae) in a greenhouse using the predacious mite Phytoseiulus persimilis AthiasHenriot (Phytoseiidae)," The Canadian Entomologist, vol. 93, no. 6, pp. 437-443, 1961.

[4] T. J. Legowski, "Experiments on predator control of the glasshouse red spider mite on cucumbers," Plant Pathology, vol. 15, pp. 34-41, 1966.

[5] N. French, W. J. Parr, H. J. Gould, J. J. Williams, and S. P. Simmonds, "Development of biological methods for the control of Tetranychus urticae on tomatoes using Phytoseiulus persimilis," Annals of Applied Biology, vol. 83, no. 2, pp. 177-189, 1976.

[6] J. C. van Lenteren, "Commercial availability of biological control agents," in Quality Control and Production of Biological Control Agents: Theory and Testing Procedures, J. C. van Lenteren, Ed., pp. 167-179, CABI, Oxon, UK, 2003. 
[7] J. C. van Lenteren, “The state of commercial augmentative biological control: plenty of natural enemies, but a frustrating lack of uptake," BioControl, vol. 57, no. 1, pp. 1-20, 2012.

[8] L. A. Gilkeson, "Mass rearing of phytoseiid mites for testing and commercial application," in Advances in Insect Rearing for Research and Pest Management, T. E. Anderson and N. C. Leppla, Eds., pp. 489-506, Westview Press, Boulder, Colo, USA, 1992.

[9] S. S. Kamburov, "Methods of rearing and transporting predacious mites," Journal of Economic Entomology, vol. 59, pp. 875877, 1966.

[10] G. T. Scriven and J. A. McMurtry, "Quantitative production and processing of tetranychid mites for large-scale testing of predator production," in Journal of Economic Entomology, vol. 64, pp. 1255-1257, 1971.

[11] T. Kostiainen and M. A. Hoy, "Egg-harvesting allows large scale rearing of Amblyseiulus finlandicus (Acari: Phytoseiidae) in the laboratory," Experimental \& Applied Acarology, vol. 18, pp. 155165, 1994.

[12] T. L. Theaker and N. V. Tonks, "A method of rearing the predaceous mite Phytoseiulus persimilis (Acarina: Phytoseiidae)," Journal of the Entomological Society of British Columbia, vol. 74, pp. 8-9, 1977.

[13] W. P. J. Overmeer, "Rearing and handling," in Spider Mites: Their Biology, Natural Enemies, and Control, W. Helle and M. W. Sabelis, Eds., pp. 161-170, Elsevier, Amsterdam, The Netherlands, 1985.

[14] J. A. McMurtry, G. T. Scriven, S. N. Newberger, and H. G. Johnson, "Methodologies of rearing, introducing, and establishing phytoseiid mites," in Proceedings of the ADAP Crop Protection Conference, vol. 134 of Research Extension, pp. 104110, HITAHR, Honolulu, Hawaii, USA, 1989.

[15] C. I. T. Shih, "Automatic mass-rearing of Amblyseius womersleyi (Acari: Phytoseiidae)," Experimental and Applied Acarology, vol. 25, no. 5, pp. 425-440, 2001.

[16] D. Fournier, P. Millot, and M. Pralavorio, "Rearing and mass production of the predatory mite Phytoseiulus persimilis," Entomologia Experimentalis et Applicata, vol. 38, no. 1, pp. 97-100, 1985.

[17] M. G. Rojas and J. A. Morales-Ramos, “Tri-trophic level impact of host plant linamarin and lotaustralin on Tetranychus urticae and its predator Phytoseiulus persimilis," Journal of Chemical Ecology, vol. 36, no. 12, pp. 1354-1362, 2010. 

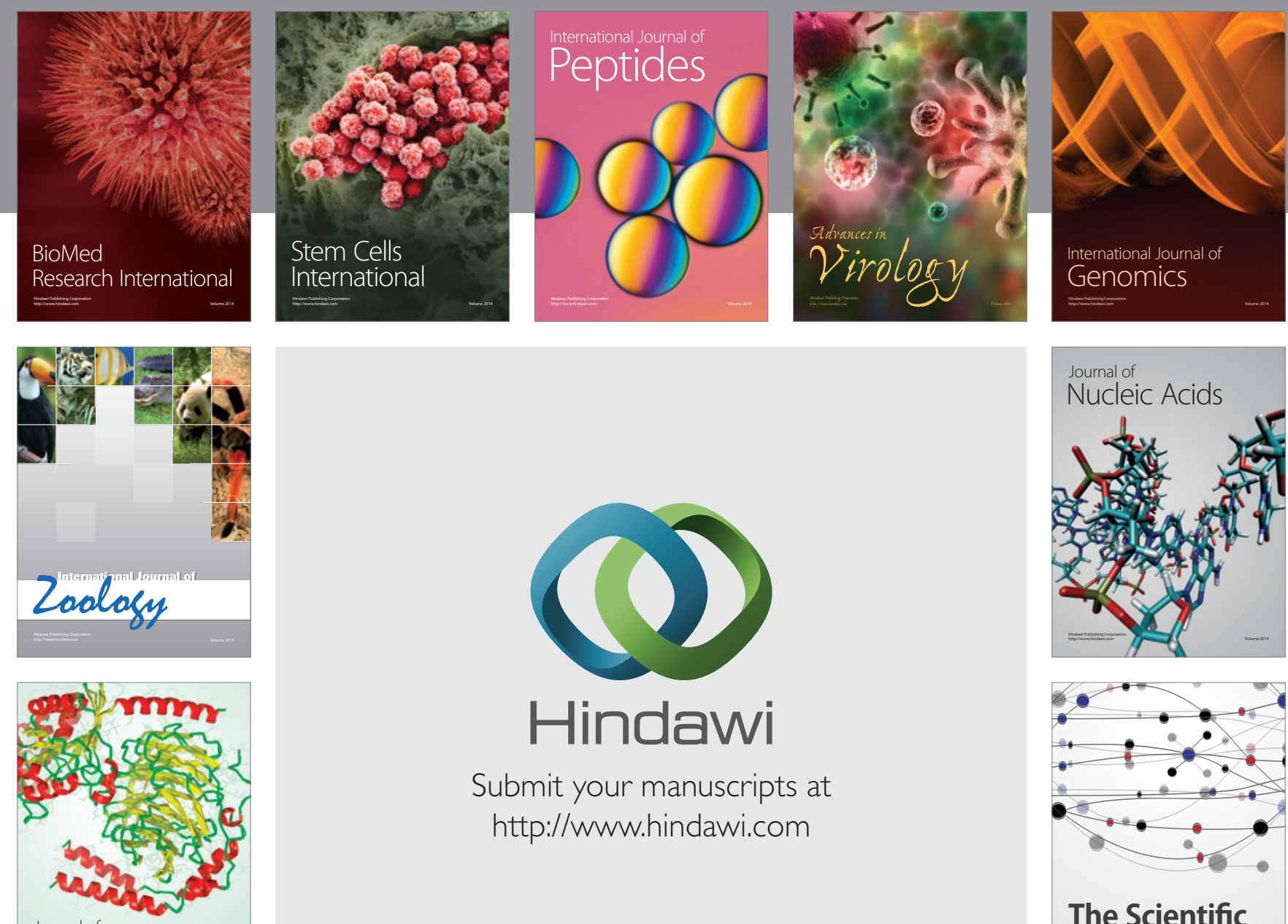

Submit your manuscripts at

http://www.hindawi.com

Journal of
Signal Transduction
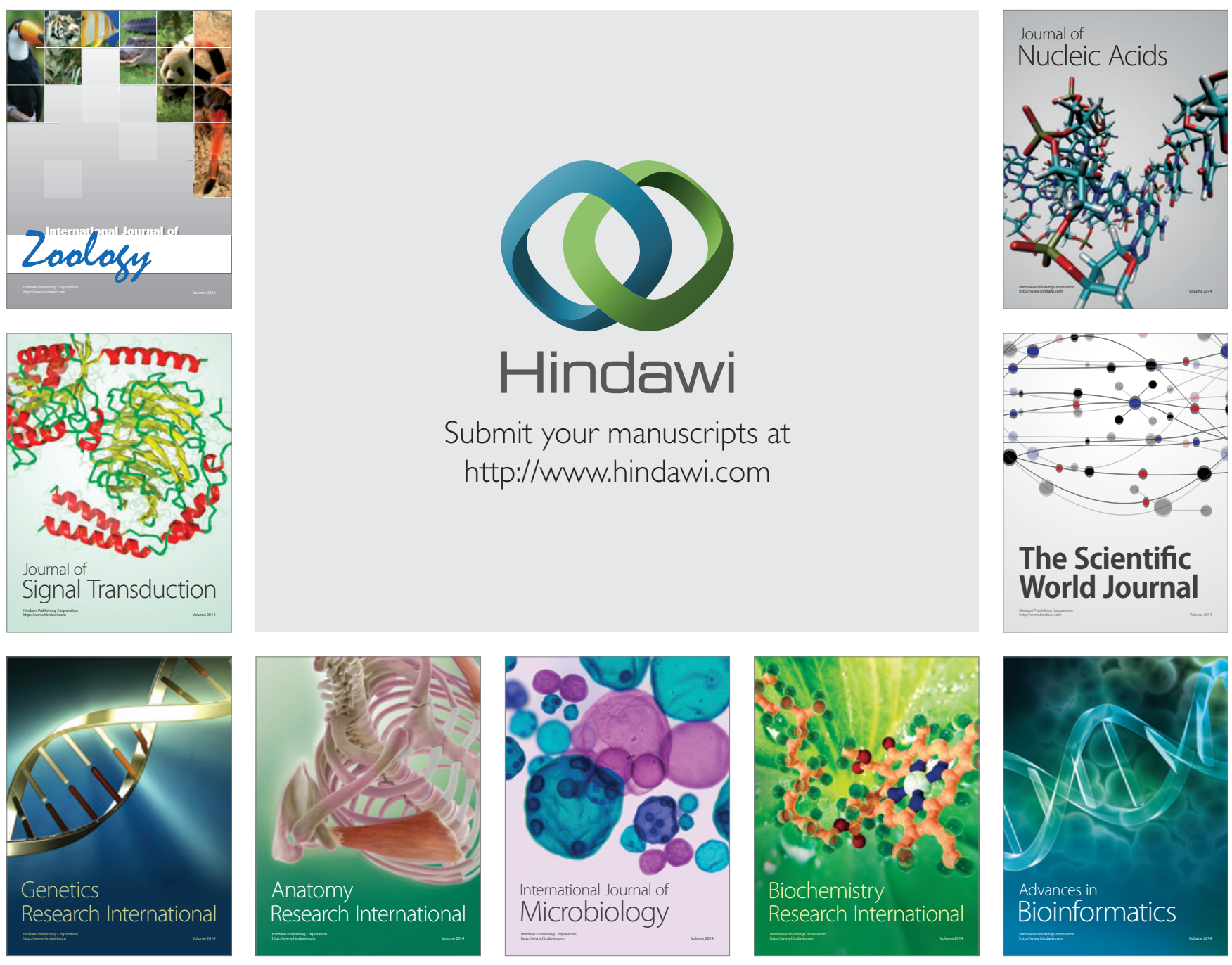

The Scientific World Journal
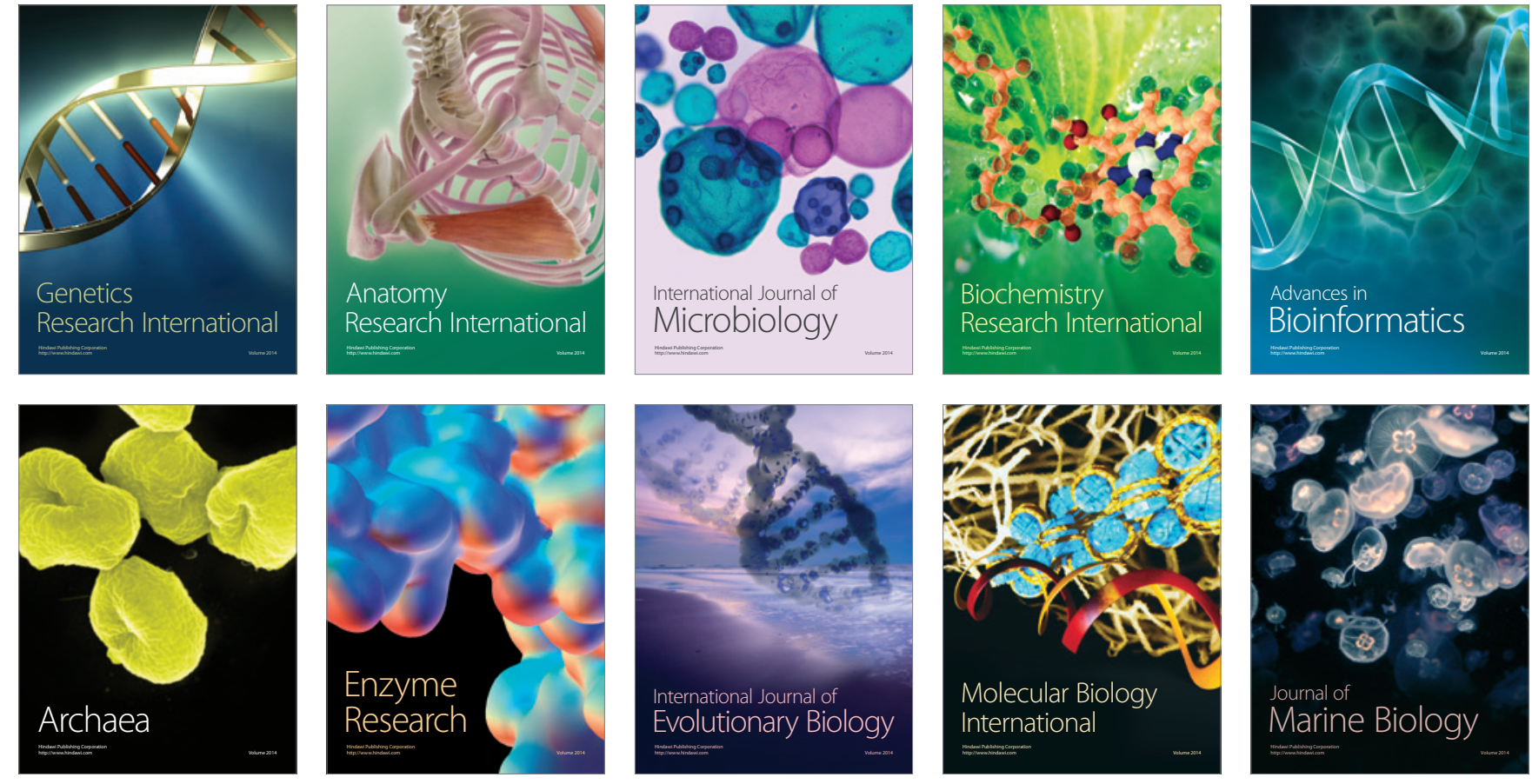